\title{
Effect of Cellulosic and Polymethacrylic Polymers on Drug Content, Particle Morphology, and Carbamazepine Release Profiles from Sustained Release Ethyl Cellulose Microspheres
}

\author{
Sams Mohammad Anowar Sadat, Md. Saiful Islam, Sheikh Tasnim J ahan, \\ J akir Ahmed Chowdhury and Reza-ul J alil
}

Department of Pharmaceutical Technology, Faculty of Pharmacy, University of Dhaka

Dhaka-1000, Bangladesh

\begin{abstract}
Emulsion-solvent evaporation technique was used to prepare Carbamazepine (CBZ) loaded Ethyl Cellulose (EC) microspheres. Cellulosic polymers (HPMC $4.5 \mathrm{cps}, 15 \mathrm{cps}$ ) and polymethacrylic polymers (Eudragit E100, Eudragit RL PO, Eudragit RS PO) were added with EC at 10\% (w/w) of EC. The effect of these polymers on drug content, particle size, and CBZ release rate were evaluated. The CBZ encapsulation efficiency and the drug content varied from $85 \%$ to $95 \%$ and from $42 \%$ to $45 \%(\mathrm{w} / \mathrm{w})$, respectively. The mean particle diameter varied from 460 to $730 \mu \mathrm{m}$. In vitro release study for 8 hours was conducted in $1 \%(\mathrm{w} / \mathrm{v})$ sodium dodecyl sulfate solution. All the polymers reduced the release of $\mathrm{CBZ}$ and a statistically significant variation in release rate was observed from polymer to polymer.
\end{abstract}

Key words: Carbamazepine, Ethyl Cellulose, Sustained release microspheres, Emulsion-Solvent Evaporation Technique.

\section{INTRODUCTION}

Epilepsy is one of the more common neurologic disorders affecting at least 0.5 to $1 \%$ of any population. ${ }^{1,2}$ Antiepileptic drugs (AEDs) remain the cornerstone of therapy. The primary treatment goal is to achieve complete control of seizures without adverse events. However, for many patients becoming seizure-free remains a challenge. Toxicity and poor adherence to AED therapy are two common reasons why achieving seizure freedom is problematic. $^{3,4}$

Correspondence to:

Reza-ul Jalil

Tel: +880-2-9120325; Fax: +880-2-8615583

E-mail: raju1559@yahoo.com

Dhaka Univ. J. Pharm. Sci. 9(2): 75-82, 2010 (December)
Carbamazepine (CBZ), a tricyclic iminostilbene derivative, is among the most important antiepileptic drugs. It is the drug of choice for simple and complex partial and secondarily generalized seizures ${ }^{5}$ as well as being a mood stabilizer in manic-depressive patients. ${ }^{6}$

CBZ belongs to class II of the biopharmaceutical classification system. Compounds in this category have high intestinal permeability and low water solubility. Subsequently, the bioavailability of such compounds is limited by their solubility in water. There have been several reports concerning the polymorphism of $\mathrm{CBZ}$ and its influence on solubility and bioavailability. At least four different anhydrates and one dihydrate form have been identified for CBZ. Differences in bioavailability have been observed 
among various commercial formulations of $\mathrm{CBZ}$ as well as among the different polymorphic forms. ${ }^{7}$

During repeated administration of CBZ, its elimination half-life $\left(t_{1 / 2}\right)$ is significantly decreased due to autoinduction of its own metabolism. $\mathrm{CBZ} \mathrm{t}_{1 / 2}$ is $\sim 24 \mathrm{hr}$, after single dosing, whereas on chronic dosing it is lowered to $\sim 12 \mathrm{hr}$ under monotherapy or $\sim 8 \mathrm{hr}$ in those patients who take other enzymeinducing drugs. ${ }^{8}$

The development of sustained-release or controlled-release formulations of CBZ is therefore of therapeutic relevance and has caught the attention of the pharmaceutical industry. These extendedrelease formulations can improve medication compliance, modify AED pharmacokinetics, and provide clinicians with greater ability to individualize therapy. Various methods, including the formulation of CBZ-controlled release matrix tablets were develop $^{9-12}$ as well as CBZ-controlled release microspheres were studied. ${ }^{13}$ Bioavailability studies in patients with epilepsy have shown that the commercially available CBZ extended-release formulations are bioequivalent to the immediaterelease formulations. ${ }^{14}$ It is found that the central nervous system (CNS) side effects associated with immediate-release formulation of $\mathrm{CBZ}$ were reduced when patients were switched to an extended-release formulation. ${ }^{15}$

In the last decade, the interest in polymer blending has grown mainly due to the fact that a material property can be modified without undertaking the synthesis of a new compound. In the pharmaceutical field, polymeric blending has been exploited as a way to modify the release properties of drugs from matrix delivery systems. Matrix properties of microspheres such as swelling, permeability, and also biodegradation can be varied in order to obtain a proper drug release profile. ${ }^{16,17} \mathrm{In}$ several instances, the modification of the release profile of a drug is achieved when a second polymer presenting a hydrophilic nature is added to the microsphere formulation, which is generally based on hydrophobic polymers. It has been demonstrated that the presence of a hydrophilic polymer in the matrix system increases the water content of particles and/or induces pore formation improving both dissolution and diffusion of the drug. ${ }^{16,18}$ On the other hand, presence of a hydrophobic polymers impart an opposite effect and ultimately retard the dissolution property of the drug. In this context, the aim of this study is to evaluate the effect of the addition of cellulosic polymers, acrylic polymers on the morphology of CBZ microspheres and, consequently, on the release profile of Carbamazepine (CBZ).

\section{MATERIALS AND METHODS}

Carbamazepine was received as a generous gift from Incepta Pharmaceuticals Ltd.), Ethyl Cellulose (Ethocel $20 \mathrm{cps}$, Colorcon, USA), HPMC $4.5 \mathrm{cps}$ (Samsung, Korea), HPMC 15 cps (Samsung, Korea), Kollicoat MAE 100 P (BASF, Germany), Eudragit E100 (Degussa, Germany), Eudragit L100 (Degussa, Germany), Eudragit RSPO (Degussa, Germany), Eudragit RLPO (Degussa, Germany). Liquid Paraffin (MERCK, Germany), Span 80 (LOBA CHEMIE, India), Methanol (MERCK, Germany), Acetonitrile (MERCK, Germany), n-Hexane (MERCK, Germany) were used in this study from the indicated sources.

Preparation of CBZ microspheres. CBZ loaded EC microspheres were prepared using the emulsification and solvent evaporation technique. ${ }^{19}$ Briefly, $15 \mathrm{~mL}$ methanol solution containing CBZ (internal phase) was emulsified in $100 \mathrm{~mL}$ of mineral oil containing $1.5 \%(\mathrm{w} / \mathrm{v})$ Span 80 (external phase) using a stirrer (Heidolph No. 5011, Heidolph, England). The emulsion was continuously stirred for $2 \mathrm{hrs}$ at room temperature to allow the methanol evaporation from the internal phase. The microspheres, produced, were filtered, washed three times, each with $50 \mathrm{~mL}$ of $\mathrm{n}$-hexane, and then dried by a vacuum dryer (VEEGO, India). The drug to polymer ratio and the total polymer concentration in the internal phase were $1: 1$ and $2.0 \%(\mathrm{w} / \mathrm{v})$, respectively, for all tested formulations. When the EC/second polymer mixture was as wall material, the second polymer was used at $10 \%(\mathrm{w} / \mathrm{w})$ of EC. 
Encapsulation efficiency and CBZ content. The CBZ content was determined after dissolving 30 $\mathrm{mg}$ of microspheres accurately weighed in acetonitrile. The CBZ concentration was determined by UV-VIS Spectrophotometer (UV mini-1240, SHIMADZU CORP., Kyoto, Japan) at $284 \mathrm{~nm}$. The encapsulation efficiency of CBZ was calculated as being the difference between the amount of drug initially added to the formulation and the amount found in the microspheres after UV analysis. Finally, the $\mathrm{CBZ}$ content in the microspheres $(\% \mathrm{w} / \mathrm{w})$ was estimated. All the analyses were carried out in triplicate.

Particle size determination. Microspheres size distribution was analyzed by laser diffraction technique using Mastersizer 2000 (MALVERN, UK). Particle size distribution was measured by Dry Dispersion technique. Volume mean diameter (D [4, 3]) was used to express average particle size in $\mu \mathrm{m}$. Specific surface area $\left(\mathrm{m}^{2} / \mathrm{gm}\right)$ of the microspheres was also determined.

In vitro dissolution study. In vitro $\mathrm{CBZ}$ release studies were carried out in $900 \mathrm{ml}$ of $1 \%$ (w/v) sodium dodecyl sulfate solution maintained at $37^{\circ} \pm$ $0.5{ }^{\circ} \mathrm{C}$ using a standard USP XXIII apparatus with paddle stirring at $75 \mathrm{rpm}$ (Electrolab, India). Colorless hard gelatin capsules (size 00) were filled with microspheres corresponding to $100 \mathrm{mg}$ of CBZ and were placed into the dissolution media. Samples were withdrawn at regular time intervals for 8 hours and were assayed spectrophotometrically at $284 \mathrm{~nm}$. The sink condition was maintained using fresh sodium dodecyl sulfate solution. Statistical analysis was performed on the area under the curve (AUC) calculated by the linear trapezoidal method.

Kinetic models. Based on in-vitro release studies, all data were fitted to various kinetic equations to find out the mechanism of drug release from the CBZ loaded microspheres. In this study, four kinetic models zero-order kinetics (Eq. 1); firstorder equation (Eq. 2); square-root of time equation (Eq. 3) and Korsenmeyer-Peppas equation (Eq. 4) used were:

Zero-order equation: $Q_{t}=k_{0} t \ldots \ldots \ldots \ldots . .1$
First-order equation: $\ln Q_{t}=\ln Q_{0}-k_{1} t \ldots 2$

Higuchi equation based on Fickian diffusion :

$$
Q_{t}=k_{H} \sqrt{ } t \ldots \ldots \ldots . .3
$$

Where, $Q$ is the amount of drug release in time t, $Q_{0}$ is the initial amount of drug in the microsphere and $k_{0}, k_{l}$ and $k_{H}$ are rate constant of zero order, first order and Higuchi rate equations respectively. In addition to these basic release models, there are several other models as well. One of them is Peppas and Korsemeyer equation. ${ }^{20,21}$

Korsemeyer-Peppas equation: $M_{t} / M_{\infty}=k t^{n} . .4$

Where $\mathrm{M}_{\mathrm{t}}$ is the amount of drug release at time $\mathrm{t}$ and $\mathrm{M}_{\infty}$ is the amount release at time $\mathrm{t}=\infty$, thus $M_{t}$ $/ M_{\infty}$ is the fraction of drug released at time $\mathrm{t}, \mathrm{k}$ is the kinetic constant and $\mathrm{n}$ is the diffusion exponent which can be used to differentiate both mechanism for both solvent penetration and drug release.

\section{RESULTS AND DISCUSSION}

CBZ microspheres were successfully prepared by emulsion-solvent evaporation technique. The microspheres prepared were hard, spherical and free flowing. Figure 1 shows a photograph of $\mathrm{CBZ}$ microsphere formulated with EC.

Encapsulation efficiency and drug content. The encapsulation efficiency of CBZ and the drug content in the microspheres varied from 81 to $95 \%$ and from 39 to $45 \%(\mathrm{w} / \mathrm{w})$, respectively. (Table 1). In case of blank, containing no other polymer, the encapsulation efficiency and CBZ content were $81.5 \%$ and $39.75 \%$ respectively. While other polymers were added with $\mathrm{EC}$ at a $10 \%(\mathrm{w} / \mathrm{w})$ level of EC, both CBZ content and encapsulation efficiency were increased. Though in small extent, significant increased in both CBZ content and encapsulation efficiency was observed which suggests that encapsulation efficiency of EC polymer was increased while mixed with the polymers. Gel forming nature of the cellulosic polymers and presence of quaternary ammonium groups in the polymethacrylates made more CBZ to entrap inside the matrix during the preparation of microspheres. ${ }^{22,23}$ 
A statistical correlation was also found where the $\mathrm{F}_{\text {crit }}$ and $\mathrm{P}$ values were 4.6 and $<0.0001$ respectively (ANOVA, single factor).

Morphological examination and particle size determination. Spherical particles with smooth surface were produced while they were observed under optical microscope. Usually, when the emulsion-solvent evaporation method is used, the increase in the solvent elimination rate during microencapsulation leads to the formation of rougher particles. ${ }^{24}$ In this case, a faster solvent elimination was provided by using highly volatile acetonepolymer solution where EC was used only $2 \%(\mathrm{w} / \mathrm{v})$ of the external phase.

The mean diameter of the particles varied from 460 to $730 \mu \mathrm{m}$, according to the formulation tested (Table 1). Particles containing only EC were in the size range of 421.3-463.5 $\mu \mathrm{m}$. As the second polymers were added in the individual formulation, particle sizes were found increased. Especially HPMC 15 cps produced largest particles where the particles were 702.1-812.1 $\mu \mathrm{m}$ in size. Swelling tendency of the polymer might be attributed to these larger particles (Alderman 1984). Particles prepared with HPMC 4.5 cps were also comparatively larger than the blank. Microspheres were also prepared with the polymethacrylates (Eudragit E100, Eudragit RL PO and Eudragit RS PO) and particles became larger after the addition of these polymers. Particles were 626-745 $\mu \mathrm{m}$ for these polymethacrylates polymers. It is found that Eudragit E100 increased the particle size and size was 643.1-678.1 $\mu \mathrm{m} .{ }^{25}$ Eudragit RS PO produced comparative larger particles than Eudragit RL PO. Both these polymers increased particle size and this might be the result of higher amount CBZ present in the microsphere matrix. Release profiles of the drugs from microspheres are recognized as being dependent on the particle size. In most cases, the smaller the mean particle diameter, the shorter the diffusion path for drug releases, and consequently, the faster the release rate. ${ }^{26}$

Table 1. Encapsulation efficiency, drug content, mean particle size of CBZ microsphere formulation (n=3).

\begin{tabular}{|c|c|c|c|c|}
\hline Formulation $(\mathrm{n}=3)$ & Coating Polymer & $\begin{array}{l}\text { Encapsulation } \\
\text { Efficiency (\%) }\end{array}$ & $\begin{array}{c}\text { CBZ Content } \\
(\% \mathrm{wt} / \mathrm{wt})\end{array}$ & $\begin{array}{l}\text { Particle Mean } \\
\text { Diameter }(\mu \mathrm{m})\end{array}$ \\
\hline \multirow[t]{3}{*}{ Blank (Only Ethocel) } & No & 81.50 & 39.75 & $463.5 \pm 21.12$ \\
\hline & & & & $421.3 \pm 18.23$ \\
\hline & & & & $456.1 \pm 14.56$ \\
\hline \multirow[t]{3}{*}{$\mathrm{H} 4.5$} & HPMC $4.5 \mathrm{cps}$ & 88.26 & 44.13 & $500.8 \pm 21.23$ \\
\hline & & & & $531.1 \pm 34.22$ \\
\hline & & & & $501.1 \pm 24.54$ \\
\hline \multirow[t]{3}{*}{ H15 } & HPMC $15 \mathrm{cps}$ & 90.33 & 45.17 & $732.8 \pm 12.12$ \\
\hline & & & & $812.1 \pm 31.51$ \\
\hline & & & & $702.1 \pm 23.34$ \\
\hline \multirow[t]{3}{*}{ E 100} & Eudragit E100 & 91.13 & 43.32 & $667.7 \pm 16.65$ \\
\hline & & & & $643.1 \pm 18.45$ \\
\hline & & & & $678.1 \pm 21.32$ \\
\hline \multirow[t]{3}{*}{ RLPO } & Eudragit RL PO & 85.79 & 42.89 & $635.9 \pm 21.71$ \\
\hline & & & & $626.1 \pm 11.67$ \\
\hline & & & & $677.3 \pm 31.23$ \\
\hline \multirow[t]{3}{*}{ RSPO } & Eudragit RS PO & 94.44 & 47.72 & $665.8 \pm 26.31$ \\
\hline & & & & $712.1 \pm 11.78$ \\
\hline & & & & $745.1 \pm 22.01$ \\
\hline
\end{tabular}

In vitro release studies. $\mathrm{CBZ}$ release profiles for all tested formulations are shown in Figure 2. In this study, sink conditions were assured by the addition of $1 \%(\mathrm{w} / \mathrm{w})$ sodium dodecyl sulfate to the release medium, because CBZ solubility was nearly twelve times greater than the concentration of the drug after its complete release from the microspheres. ${ }^{13}$ As can be observed in Figure 1, CBZ microspheres with only 
ethocel (blank) released nearly $100 \%$ of CBZ after 8 hours. This might be due to the fact that ethyl cellulose (Ethocel $20 \mathrm{cps}$ ) itself is a controlled release polymer especially for microsphere preparation. ${ }^{27,28}$ While a second polymer was used in the internal polymeric phase during microsphere preparation, a more decreased CBZ release was observed from the formulations. The CBZ release was $93.2 \%$ and $90.2 \%$ for HPMC 4.5 cps and HPMC 15 cps respectively. Hydrophilic nature of both of these cellulosic polymers might be attributed to this reduced CBZ release. When exposed to the dissolution medium, the solvent penetrates into the free spaces between macromolecular chains of HPMC. After salvation of

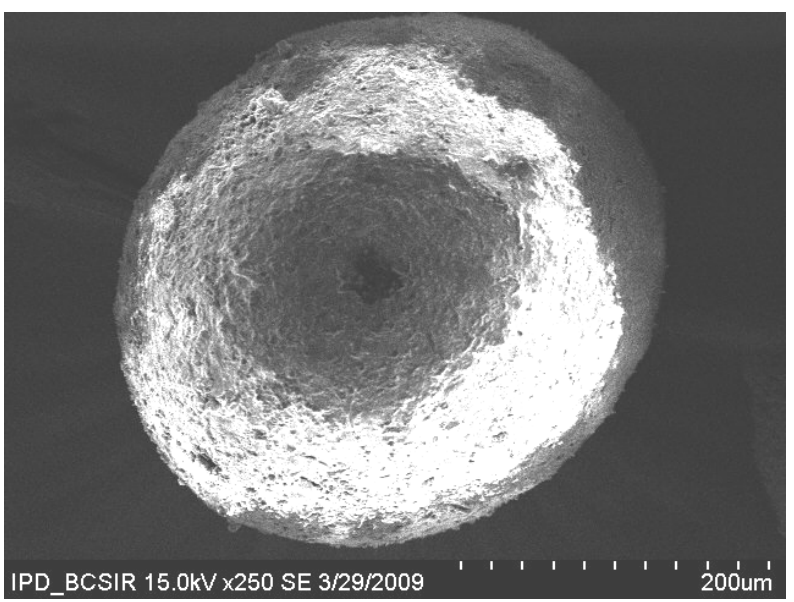

Figure 1. Scanning electron microscopic (SEM) photograph of ethyl cellulose microsphere containing Carbamazepine.

Polymethacrylate polymers are also used and a good controlled release of CBZ is also observed (Figure 1). CBZ release was $80.1 \%$ and $87.2 \%$ for Eudragit RS PO and Eudragit RL PO respectively. That is, comparing with that of Eudragit RS PO microspheres, the release rate of the Eudragit RL PO microspheres was a little higher. It might be due to the presence of highly permeable polymer, Eudragit RL PO, which increased the porosity of the matrix and thus accelerates the drug release. ${ }^{32}$ This might be attributed to the difference in the content of quaternary ammonium group. the polymer chains, the dimensions of the polymer molecule increase due to the polymer relaxation by the stress of the penetrated solvent. This phenomenon is defined as swelling and it is characterized by the formation of a gel-like network surrounding the microsphere. This swelling and hydration property of HPMC causes an immediate formation of a surface barrier around the microsphere that stopped the immediate release of the drug. The early slow release was immediately followed by an increased release of CBZ and this might be due to the erosion of the matrix which took place after complete hydration of the outer layer. ${ }^{22,29-31}$

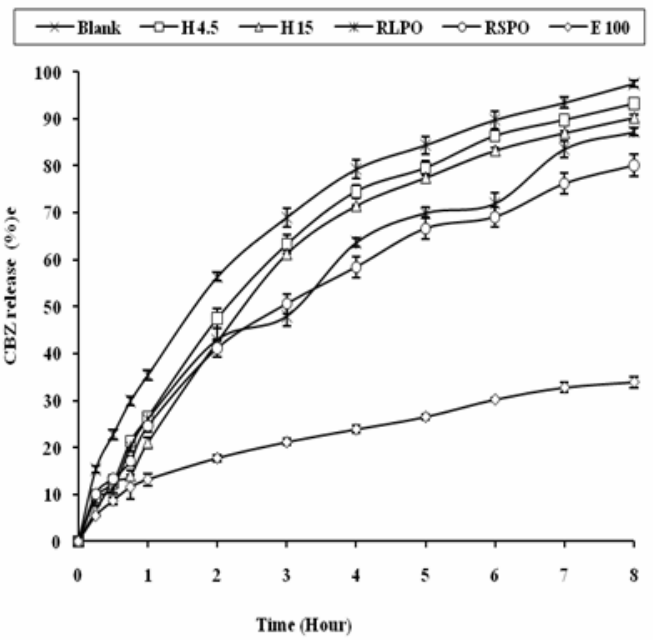

Figure 2. Zero order release of Carbamazepine from ethyl cellulose microspheres

As we know, the content of the quaternary ammonium group of the Eudragit RL PO microsphere (10\%) is higher than that of the Eudragit RS PO microsphere (5\%). So, in the Eudragit RL PO microspheres, the drug might be dispersed evenly in the matrix of the polymer and the surface would be loose, due to the high charge density. On the other hand, in the case of Eudragit RS PO microsphere, lower charge density produces more packed structures than those of Eudragit RL PO microspheres.

Eudragit E100 is a polymethacrylic polymer consisting of 1:2:1 molar ratio of methol 
methacrylate, N, N - dimethylaminoethyl methacrylate, and butyl methacrylate monomers. Eudragit E100 has been widely used in pharmaceutical industry for various coating applications as well as for microencapsulation and nanoparticle synthesis purpose. ${ }^{33}$ Eudragit E100 also showed a good release retarding capacity. Only $33.1 \%$ CBZ was released while Eudragit E100 was used.
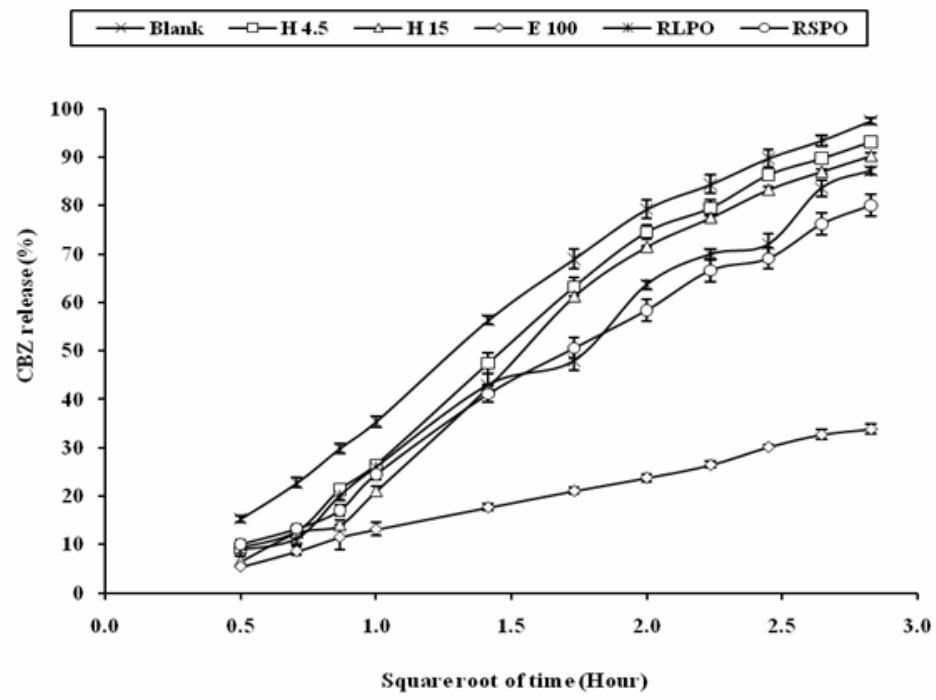

Figure 3. Higuchi release of Carbamazepine from ethyl cellulose microspheres.

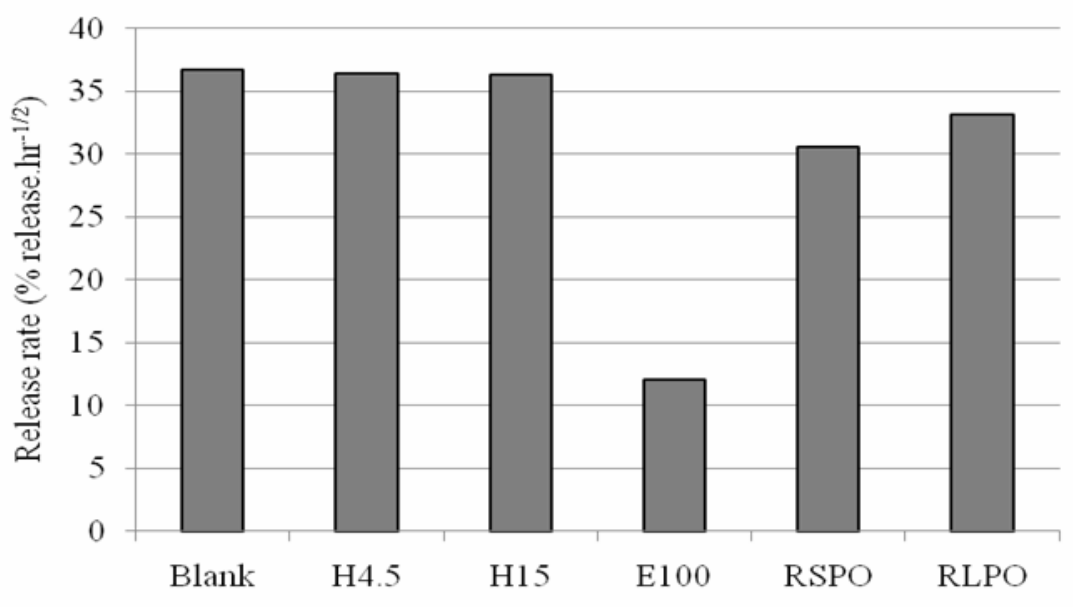

Figure 4. Release rate of CBZ from different microsphere formulations.

Kinetic mechanism of CBZ release. Release data were also fitted in first order model, Higuchi model, Peppas-Korsmeyer model. The release rate constants according to different mechanisms were calculated and are shown in Table 2. From the data, it is clearly seen that release from blank (only EC), E 100 and RL PO microsphere formulations followed
Higuchi model whereas that of H4.5, H15 and RS PO followed first order model. As we know that a value of $\mathrm{n}=0.45$ indicates Fickian or case I release, $0.45<$ $\mathrm{n}<0.89$ indicates non-Fickian or anomalous release, $\mathrm{n}=0.89$ indicates case II release and $\mathrm{n}>0.89$ indicates super case II release. So, CBZ release from blank (0.546), HPMC 4.5 cps (0.7059), HPMC 15 cps (0.7943), Eudragit E 100 (0.5037) and Eudragit 
RL PO (0.6918) was dominated by non-fickian or anomalous type mechanism. On the other hand, only Eudragit RS PO formulated microsphere followed super case II mechanism. However, it can be concluded that the effect of diffusion on drug release through EC material was more dominant than the effect of polymer relaxation as the values of $n$ were nearer to 0.6 in case blank and Eudragit E100. In contrast, in case of HPMC $4.5 \mathrm{cps}$, HPMC $15 \mathrm{cps}$ and Eudragit RL PO, the effect of EC relaxation on CBZ release was more than the effect of diffusion through the wall formed by EC as the values of $n$ were nearer to 0.7 .

Table 2 Mean kinetic release of CBZ from different microsphere formulations.

\begin{tabular}{|c|c|c|c|c|c|c|}
\hline $\begin{array}{l}\text { Formula } \\
\text { Kinetic }\end{array}$ & $\begin{array}{c}\text { Blank } \\
\text { (Only Ethocel) }\end{array}$ & $\mathrm{H} 4.5$ & H15 & E100 & RL PO & RS PO \\
\hline \multicolumn{7}{|c|}{ Zero Order Model } \\
\hline$r^{2}$ & 0.894 & 0.927 & 0.930 & 0.929 & 0.935 & 0.946 \\
\hline $\mathrm{K}$ & 11.419 & 11.946 & 11.982 & 3.800 & 9.7 & 10.61 \\
\hline \multicolumn{7}{|c|}{ First Order Model } \\
\hline$r^{2}$ & 0.9813 & 0.9985 & 0.9934 & 0.9547 & 0.998 & 0.9902 \\
\hline $\mathrm{K}$ & 0.178 & 0.143 & 0.1303 & 0.0206 & 0.1096 & 0.0923 \\
\hline \multicolumn{7}{|c|}{ Higuchi Model } \\
\hline$r^{2}$ & 0.987 & 0.9807 & 0.9793 & 0.997 & 0.99 & 0.987 \\
\hline $\mathrm{K}$ & 36.737 & 37.41 & 39.649 & 12.056 & 30.581 & 33.188 \\
\hline \multicolumn{7}{|l|}{ Peppas Model } \\
\hline$r^{2}$ & 0.9889 & 0.9809 & 0.9809 & 0.9918 & 0.982 & 0.9674 \\
\hline $\mathrm{n}$ & 0.546 & 0.7059 & 0.7943 & 0.5037 & 0.6918 & 0.9718 \\
\hline $\mathrm{T}_{50 \%}$ (Hour) & 1.954 & 2.728 & 3.106 & $>8$ & 3.038 & 3.703 \\
\hline
\end{tabular}

\section{CONCLUSION}

The present study provides evidence that the encapsulation of CBZ to EC microspheres, either as a single polymer or mixture with another coating polymer, was a successful attempt to control the release of CBZ. CBZ microspheres formulations, prepared with mixtures of $\mathrm{CBZ}$ and core forming polymer (either single EC or mixture of EC and coating polymer) at a ratio of $1: 1$, showed good mean dissolution values $\left(\mathrm{T}_{50 \%}\right)$. Especially one formulation with Eudragit E 100 9E100) was selected based on its dissolution $\mathrm{T}_{50 \%}$ which was greater than 8 hours. This microsphere mixture will be subject to future experiments to study their in vivo performance in animals, which would be beneficial in examining their practicality as drug delivery system.

\section{ACKNOWLEDGEMENTS}

The author is very grateful to Incepta Pharmaceuticals Ltd., Bangladesh for providing the sample of carbamazepine and other raw materials. The authors also thank Incepta Pharmaceuticals Ltd, Bangladesh for giving the permission to use the particle size analyzer.

\section{REFERENCES}

1. Vickrey, B.G. 1995. Special issue: advances in the measurement of health-related quality of life in epilepsy. Qual. Life Res. 4, 83-85.

2. Annegers, J.F. 1997. Epidemiology of epilepsy. In the treatment of Epilepsy: Principles and Practice, 2nd ed., Wyllie E, ed., 165-172. Baltimore: Williams \&Wilkins.

3. Pedley, T.A., Scheuer, M.L., and Walczak, T.S. 1995. Epilepsy. In Merritt's Textbook of Neurology, 9th ed., Rowland LP, ed., 845-68. Baltimore: Williams \& Wilkins.

4. Leppik, I.E. 2002. Contemporary Diagnosis and Management of the Patient with Epilepsy. 6th ed. Newtown, PA: Handbooks in Healthcare, 119-127.

5. Karceski, S., Morrell, M., and Carpenter, D. 2001. The expert consensus guideline series: treatment of epilepsy. Epilepsy Behav., 2, A1-A50.

6. DeVane, L. 1990. Fundamentals of monitoring psychoactive drug therapy in drug therapy for mood disorders (E) intraclass comparisons of antidepressants and mood stabilizers. Baltimore: Williams \& Wilkins, 128-130. 
7. Meyer, M.C., Straughn, A.B., Jarivi, E. J.,Woods, G.C., Pelsor, F.R., and Shah, V.P. 1992. The bioinequivalance of carbamazepine tablets with a history of clinical failures. Pharmaceut. Res. 9, 1612-1616.

8. Ramsay, R.E., McManus, D.Q., Guterman, A., Briggle, T. H., Vazquez, D., and Perchalski, R. 1990. Carbamazepine metabolism in humans: effect of concurrent anticonvulsant therapy. Therapeut. Drug Monit. 12, 235-241.

9. Giunchedi, P., Maggi, U., Conte, U., and La, Manna, A. 1993. Linear extended release of water insoluble drug, carbamazepine, from erodible matrices. Int. J. Pharmaceut., 94, 15-22.

10. Ikinici, G., Capan,Y., Senel, S., Dalkara, T., and Hincal, A. A. 1999. Formulation and in-vitro/in-vivo investigation of carbamazepine controlled-release matrix tablets. Pharmazie. 54, 139-141.

11. Rafiee-Tehrani, M., Zehtabchii, B., Aghaii-Moghaddam, F., and Mehdizadehi, A. 2000. Effect of different polymers on the release characteristics of carbamazepine from stable controlled-release tablets prepared by the air suspension and wet granulation techniques. Acta Pharmaceutica. 50, 291301.

12. Barakat, N. S., Elbagory, I. M. and Almurshedi, A. S. 2003. Evaluation of prolonged release carbamazepine granules prepared from lipophilic matrices. 6th Saudi Pharmaceutical International Conference, October 6-9, 2003.

13. Betina ZANETTI-RAMOS, Marli SOLDI, Valdir SOLDI \& Elenara LEMOS-SENNA. 2006. The Effect of Polyethylene Glycol on Drug Content, Particle Morphology, and Carbamazepine Release Profiles of Sustained Release Microspheres prepared from Cellulose Acetate Butyrate. Acta Farm. Bonaerense. 25, 177- 83.

14. Garnett,W. R., Levy, B., McLean, A.M., et al. 1998. Pharmacokinetic evaluation of twice-daily extended-release carbamazepine (CBZ) and four-times-daily 415 immediaterelease CBZ in patients with epilepsy. Epilepsia 39, 274279

15. Miller, A., Bergey, G. and Krauss, G. 2002. Conversion from immediate- to extended-release carbamazepine markedly reduces CNS-related side effects in patients with partial-onset epilepsy. Epilepsia 43 (Suppl. 7), 196.

16. Huatan, H., Collett, J.H., Attwood, D and Booth, C. 1995. Preparation and characterization of poly (epsiloncaprolactone) polymer blends for the delivery of proteins. Biomaterials. 16, 1297-1303.

17. Bezemer, J. M., Radersma, R. Grijpma, D.W., Dijkstra, C.A., van Blitterswijk, C.A. and Feijen, J. 2000. Microspheres for protein delivery prepared from amphiphilic multiblock copolymers.2. Modulation of release rate. $J$. Control. Rel. 67, 249-60.

18. Khidr, S.H., Niazy, E.M. and El-Sayed, Y.M. 1998. Development and in-vitro evaluation of sustained-release meclofenamic acid microspheres. J. Microencapsulation. 15, 153-162.
19. Jalil, R. and Nixon, J.R. 1989. Microencapsulation using poly (L-lactic acid) I: Microcapsule properties affected by the preparative technique. J. Microencapsul. 6, 473-484.

20. Siepmann J.and Peppas NA. 2001. Modeling of drug release from delivery systems based on hydroxypropyl methylcellulose (HPMC). Adv Drug Del Rev. 48,139-157.

21. Costa, P. and Lobo JMS. 2001. Modelling and comparison of dissolution profiles. Eur J Pharm Sci. 13, 123-133.

22. Alderman, D.A. 1984. A review of cellulose ethers in hydrophilic matrices for oral controlled-release dosage forms. Int. J. Pharm. Tech. Prod. Mfr. 5, 1-9.

23. Kamel, A.H. E., Skar, M.S., Gamal, S.S.A. and Naggar, V.F. 2001. Preparation and evaluation of ketoprofen floating oral delivery system. Inter. J. Pharmaceutics, 220, 13-21.

24. Radwan, M.A., Price, J.C. and Jackett, R.L. 1995. In vitro Release of Disopyramide From Cellulose Acetate Butyrate Microspheres. Drug Dev. Ind. Pharm. 21, 1453-62.

25. Selvakumar Kalimuthu and Yadav, A.V. 2009. Formulation and Evaluation of Carvedilol loaded Eudragit E 100 Nanoparticles. Inter. J. PharmTech Res. 1,

26. Arabi, H., Hashemi, A. and Fooladi, M. 1996. Microencapsulation of allopurinol by solvent evaporation and controlled release investigation of drugs. J. Microencapsul. 13, 527-35

27. Ismail, N., Harris, M.S. and Nixon J.R., 1984. Particle size analysis of gelatin-acacia coacervate and ethylcellulosewalled microcapsules. J. Microcapsul. 1, 9-19

28. Nixon, J.R. and Meleka, M.R., 1984. The preparation and characterization of ethyl cellulose-walled theophylline microcapsules. J. Microcapsul. 1, 53-64.

29. Bain, J.C., Tan, S.B., Ganderton, D. and Solomon, M.S. 1998. Comparison of the in vitro release characteristics of a wax matrix and a hydrogel sustained release diclofenac sodium tablet. Drug Dev Ind Pharm. 17, 215-232.

30. Lee, B.J., Ryu, S.G. and Cui, J.H. 1999. Formulation and release characteristics of Hydroxypropyl methylcellulose matrix tablet containing melatonin. Drug Dev. Ind. Pharm. 25, 493-501.

31. Dow Chemical Company, Formulation for controlled release with METHOCEL cellulose ethers, USA, 1987.

32. Das, S.K. and Das, N.G. 1998. Preparation and in vitro dissolution profile of dual polymer (Eudragit RS 100 and RL 100) microparticles of diltiazem hydrochloride. $J$. Microencapsul. 15, 445-452.

33. Dittgen M., Durrani M. and Lehmann K. 1997. Acrylic polymers: a review of pharmaceutical applications STP Pharma Sci. 7, 403-437. 